\title{
Storytelling, Values and Perceived Resilience among Chinese, Vietnamese, American and German Prospective Teachers
}

\author{
Nile Stanley ${ }^{1, *}$, Kate Nguyen ${ }^{2}$, Hope Wilson ${ }^{1}$, Laurel Stanley ${ }^{3}$, Astrid Rank ${ }^{4}$, Yonghui Wang ${ }^{5}$ \\ ${ }^{1}$ Department of Childhood Education, Literacy and TESOL, University of North Florida, USA \\ ${ }^{2}$ The Vietnamese Institute of Educational Sciences, Vietnam \\ ${ }^{3}$ College of Humanities and Sciences, University of Phoenix, USA \\ ${ }^{4}$ Department of Educational Science, University of Regensburg, Germany \\ ${ }^{5}$ School of Psychology, Shaanxi Normal University, China
}

Copyright (C) 2015 by authors, all rights reserved. Authors agree that this article remains permanently open access under the terms of the Creative Commons Attribution License 4.0 International License

\begin{abstract}
Numerous qualitative studies, mostly with English speaking Westerners, have shown the important role of storytelling and values in promoting resilience. However, this quantitative study helps fill the gaps in the research, by investigating the mediator effects of storytelling on values and resilience of American, German, Chinese, and Vietnamese prospective teachers. The study, using path analysis, investigated how cultural differences influenced perceptions about storytelling, resilience and values. Open to change values of stimulation, self-direction, hedonism and universalism had the largest associations in the Final Model. The results of the multiple group analyses showed that the Final Model path estimates were invariant across cultural groups, but the error variances of the mean values were not invariant. Individual differences accounted for the variance more than cultural differences. The implications for educators, desiring to leverage literacy instruction with storytelling, are discussed.
\end{abstract}

Keywords Resilience, Storytelling, Values, Cross-cultural

\section{Introduction}

Prospective teachers face many academic challenges. To succeed and maintain their well-being, college learners must be resilient [31] and have the ability to bounce back or recover from stress. Resilience refers to the phenomenon that some people stay healthy and still experience well-being and satisfaction despite being exposed to intense stressors and risks, whereas other people facing comparable conditions are prone to disorders and impaired health. While debate remains what constitutes resilient behavior and how to best measure adaption to hardship, certain trends have emerged. Psychologists have moved away from vulnerability/deficit models of resilience. There has been a paradigm shift [9) from focusing on strengths as opposed to deficits, from illness to health. Resilience now is viewed as ordinary healthy development, not extraordinary.

The role of research should focus on finding assets, resources, and values within the cultural context that have been found to promote healthy outcomes [25]. Cochran-Smith [6] and Nieto [21] found that prospective teachers who reflected on their own autobiographic stories of resilience were more effective in teaching their own students.

\section{Literature Review}

\section{Storytelling, Resilience, Values and Culture}

Storytelling is the interactive art of using words and actions to reveal the elements and images of a story while encouraging the listener's imagination [20]. The genres of childhood stories recalled by adults [2] include: personal stories, folktales. literary, and blended. Storytelling is a constructivist teaching/learning approach that encourages deep and personal learning. Storytelling affirms students' cultural identities by encouraging them to express and validate what they already know as they grow in what they know [11]. Teaching with storytelling is built with constructivist learning principles [24]. Storytelling is a student-centered learning approach.

Resilience is one's ability to spring back from adversity. Resilience is the role of mental processes and behavior in 
promoting personal assets and protecting an individual from the potential negative effect of stressors. Values represent basic individual motivations and are also internalized as specific cultural practices through social institutions. Values define what is important for us, stable through time and situations, and guide choices and behavior.

Culture is a set of values, beliefs, attitudes, and behavior patterns shared by members of a society and transmitted from one generation to the next through socialization. Humans need social interactions, like storytelling experiences provided by parents, teachers, and peers to learn their culture. Culture is considered as the collective programming of the mind which distinguishes the members of one group or category of people from another [12].

A search of the ProQuest Social Sciences database was conducted for empirical studies investigating the relations among storytelling, values, resilience and culture. There were no studies found addressing all four variables simultaneously. One can speculate why this is so. For one, the relationships are varied and complex, with cause and effect difficult to distinguish. Secondly, most of the studies on storytelling are qualitative which raises concern on their objectivity. Finally, Western European culture places more value on the transmission of knowledge through the written word by reading and writing than the ancient, oral tradition of storytelling [23].

Prior studies revealed that storytelling strongly influenced an individual's resilience and decreased academic stress [10, 22]. Numerous qualitative studies showed the important role of storytelling and values in promoting resilience $[16,19,25$, 35]. Teachers' open to change value preferences such as self-direction and stimulation have been found to be significantly related to using more student-centered teaching approaches like storytelling $[14,15,34]$.

Resilience is defined differently among various populations, so scholars need to be sensitive to socio-cultural factors [9]. A likely variable candidate to mediate the relationship between storytelling and resilience is values. For example, China has a cultural value of conformity, so resilience is expressed when the individual sacrifices for the good of the group. Conversely, Germany is perceived as less traditional, so resilience is expressed through individualism. One of the leading values theories proposed by Schwartz [27] framed the analysis of the present study. The ten motivationally distinct values and the full circular structure of conflicts and compatibilities can be seen in Figure 1. This circular arrangement is divided to show four more general values organized as two pairs of conflicting higher order value dimensions [openness to change vs. conservation and self enhancement vs. self-transcendence]. Schwartz [27] contended that most people value one side of this circle more than the other.

Although people and cultures differ in their values preferences, research [28] from samples of school teachers and college students in 54 nations confirmed the universal hierarchical order of values. Known as the pan-cultural value hierarchy, it revealed distinct patterns of college students. Among prospective teachers, benevolence, self-direction, and universalism values were consistently most important; power, tradition, and stimulation values were least important; and security, conformity, achievement, and hedonism were in between.

\section{Self-Transcendence}

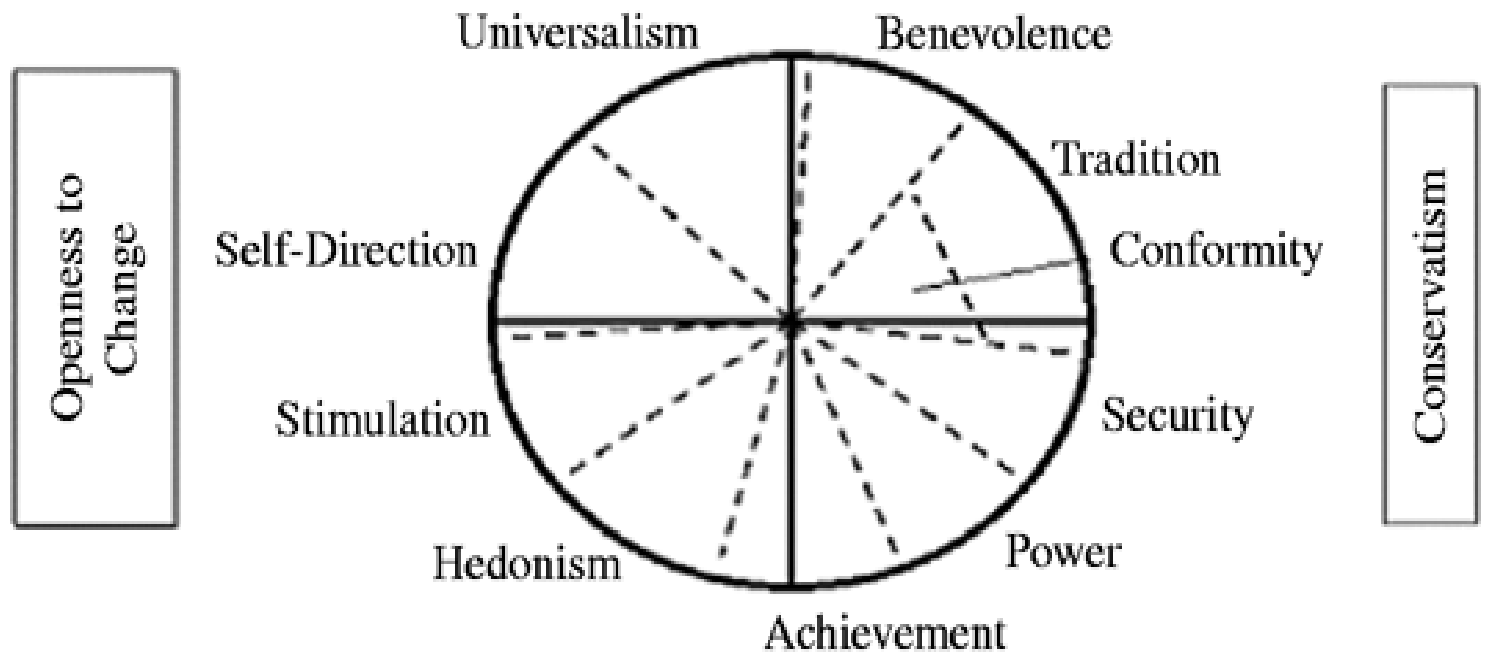

\section{Self-Enhancement}

Figure 1. Structure of personal values according to Schwartz (1992). 
Every culture has an important mission in teaching its knowledge, values, skills and commitments to child and adult members, often through storytelling [25]. Researchers in psychology, Fischer and Schwartz [8], Morris [17], Schwartz $[29,30]$ have influenced raising a question of interest -- are the differences of Eastern and Western cultures in regards to differences among storytelling, values and resilience due more to cultural factors or individual factors? How much of the variance in resilience, values, storytelling is attributed to variance in culture?

Fischer and Schwartz [8] examined the relationship between just the two variables of culture and values preference. The researchers found that analysis of multi-cultural data sets with instruments measuring priorities among abstract values, indicated that culture accounted for only $2 \%$ to $22 \%$, of the variance, depending on the instruments used. The degree of within-cultural consensus was low to moderate [though highly variable across items]. Rozin [26] stated that much of the effect of culture, and our impression of culture differences, results from the physical/social artifacts (environments, institutions) created by the culture.

\section{Present Study}

The research seeks to add to the literature to produce quantitative information about the relationships between culture, values, resilience and storytelling. The purpose of the present study was to: (1) Calculate the descriptive statistics and analyze the difference between the 4 groups in mean values for measures of storytelling, resilience, and values. (2) Calculate the correlation between storytelling and resilience and examine the extent to which the relationship is mediated by values. (3) Determine the extent a meditational model of storytelling, resilience, and value is invariant across cultures.

\section{Method}

\section{Participants}

The sample included $(n=889)$ elementary and secondary majors enrolled in teacher education programs in large urban comprehensive universities from four countries (China, $n=302$; Germany, $n=154$; United States, $n=83$; and Vietnam, $n=350$. The sample demographics were relatively reflective of the population of students from the colleges of education at their given institutions. Overall the sample was predominately female $(n=697)$, with fewer male participants $(n=192)$, which is representative of the population of education majors in general. The sample of Chinese students had the largest proportion of males (32.8\%) and the Germany had the lowest $(10.4 \%)$. Overall in the sample, the greatest number of students ages 18 to 25 years old $(n=748)$ which represented over $84 \%$ of the total sample. Germany had relatively older students $(27.9 \%)$ and China had relatively younger students $(3.6 \%)$ in the sample.

\section{Procedures}

All questionnaires were first written in English, and then translated to German, Chinese, and Vietnamese. Questionnaires were then back-tracked into English by bilingual German-English, Chinese-English, and Vietnamese-English speaking university professors not associated with the project. The five authors (two monolingual English, one bilingual German-English, one bilingual Chinese-English and one trilingual Chinese-Vietnamese-English speaker) discussed and resolved any discrepancies in the back-translations. The language versions were then altered when necessary so that the meaning of all items was as similar as possible across the four language versions of the questionnaires.

Participants were recruited through email. A database of participants was generated from four university education class email lists from China, Vietnam, the United States, and Germany. The researchers emailed participants an invitation to complete an informed consent document, and to self-report their age, gender, country of origin, and native language, Participants clicked on a link to access a secure website and completed the survey in their native language.

\section{Measures}

\section{Brief Resilience Scale (BRS)}

The BRS [31] was designed as an outcome measure to assess the adult's ability to bounce back or recover from stress. This scale consists of 6 item statements, three are positively stated (e.g. I tend to bounce back quickly after hard times) and three are negatively stated (e.g. It is hard for me to snap back when something bad happens). The BRS is scored by reverse coding the three negative items and finding the mean of the six items. The adults rate the extent to which they agree with the statements by using the following scale: 1 $=$ strongly disagree, $2=$ disagree, $3=$ neutral, $4=$ agree, $5=$ strongly agree. The Cronbach's alpha for the BRS for the American sample was found to be .86; German, .82; Chinese, .75; and Vietnamese, .82. Translations were approved by the authors of the study following iterations of translation, back-translation, and modification until a version that optimally captured the nuances of each item was obtained.

\section{The Portrait Values Questionnaire (PVQ)}

The PVQ [27] consists of 40 items designed to measure ten-value types that are ordered along two dimensions: 1) Openness to Change (stimulation, self-direction, and hedonism) vs. Conservatism (tradition, and security), and 2) Self-Enhancement (achievement, power and hedonism) vs. Self-Transcendence (universalism and benevolence). Adults respond to each item by answering how much like you is this person? The scale is a six point Likert-type scale ranging from 1 (not like me at all) to 6 (very much like me). The items include 40 short verbal portraits, gender matched to the respondent. Each portrait describes a person's goals, desires or aspirations representing 1 of the 10 basic values. Translations of the PVQ were performed by the authors, 
cross checked by volunteers, field tested with respondents, and modified for optimum comprehensibility. The reliabilities for the American sample range is from .53 (self-direction) to .75 (achievement); German .49 (self-direction) to .77 (hedonism, achievement, and stimulation); Chinese, .41 (tradition) to .79 (achievement); and Vietnamese, .29 (hedonism) to .70 (self-direction). The explanation for low reliabilities is not the result of the translation and back-translation procedures, but rather that each value is measured by a small number of items. Despite these low reliabilities, Schwartz, [27] contended that analyses in more than 200 samples from more than 60 nations from every inhabited continent support the distinctiveness of the 10 values. Despite their relatively low reliabilities in less developed countries and extreme cases, they have been found to exhibit good construct validity.

\section{Adults Perceptions about Childhood Experiences with Storytelling}

As part of the study on values and resilience, the college students were asked to complete an 18-item author developed questionnaire. The survey was developed based on statements and observations found in the review of the narrative assessment literature $[7,18,35]$ and findings from previous studies conducted by the researchers $[2,3,4]$. The Storytelling Questionnaire consisted of three subtests, measuring the dimensions of Intensity, Genres, and Impact, aimed at obtaining college students' perceptions about the frequency, types, and influence of childhood storytelling experiences using a multiple choice format. Questions required respondents to rate a series of statements according to a five point Likert-type scale. Subtest one, Intensity included six questions: (e.g., How often were you told stories? Possible responses varied from daily to never, or don't remember). Subtest two, Genres, included five questions on childhood storytelling preferences: (When you were a child were you told ... personal stories about family, folktales, literary, religious, or blended? Possible responses varied from always to never, or don't remember). The Impact subtest included 7 questions (e.g., Recalling stories that you heard and remember as a child - do they help you deal with the struggles you face as an adult? Possible responses varied from always to Never, or don't remember). For this study, the total mean score of the 18-item storytelling survey was used as a unitary measure of storytelling experience. Cronbach's alpha for the storytelling questionnaire for the American sample was found to be .89; German, .86: Chinese, .85; and Vietnamese, .81 .

\section{Data Analysis}

To address the research purposes, researchers investigated group differences for storytelling, resilience, and ten values. A structural equation model investigated the relationships between those factors and to determine if those relationships were invariant across countries. The procedures were completed in stages, beginning with an Analysis of Variance and Reliability Analysis of the factors, continuing to the development of a structural equation model with tests of goodness of fit, and finally, a multiple group analysis of the final model.

Prior to addressing the research purposes, the researchers investigated the overall relationships between the variables. This included the calculation of the internal consistency as measured by Cronbach's alpha for each variable in the model. The reliabilities, although low, were consistent with previous findings in the literature [28]. The researchers also calculated the bivariate correlations between each of the variables. As these relationships warranted further analyses, the researchers conducted the procedures to address the research purposes.

To analyze the difference between the 4 groups in mean values for measures of storytelling, resilience, and values an Analysis of Variance (ANOVA) was conducted, for each of the dependent variables (Storytelling, Resilience, and ten Values) to detect differences in the means across the four groups (students from China, Germany, United States, and Vietnam). Due to the likelihood of Type I error because of the number of dependent variables in the analyses, a Bonferroni adjustment was used.

To address examine the extent to which the relationship between storytelling and resilience is mediated by values, a structural equation model was constructed using the SPSS AMOS 22.0 software [1]. The first model tested was a saturated model, in which every path between Storytelling and the ten Values, every path from the Values to Resilience, and the direct path from Storytelling to Resilience were included. In addition, all of the covariances between the Values factors were included.

After evaluating the goodness of fit indices (including the Root Mean Square Error of Approximation (RMSEA), the Comparative Fit Index (CFI), and the Akaike's Information Criteria (AIC), as well as the chi-square test for fit), the non-significant paths were eliminated from the model to create the Trimmed Model. As these model fit indices did not indicate a well-fitting model, the Final Model included only those paths which were significant in the Trimmed model, and eliminated all non-significant covariances between the Values factors.

Finally, to determine the extent a meditational model of storytelling, resilience, and value is invariant across cultures, a multiple group analysis of the structural equation model was conducted. In the first model (Unconstrained), all path estimates between variables and all error variances between groups (China, Germany, USA, and Vietnam) were left to vary. In the second model, the path estimates between groups were constrained to be equal across groups. In the third model, the path estimates and the error variances of the variables were constrained to be equal across groups. At each stage the indices of model fit (including a chi-square analyses, RMSEA, CFI, and the AIC) as well as the change in the chi-square were examined. 
Table 1. Descriptive Statistics of Factors by Country

\begin{tabular}{|c|c|c|c|c|c|c|c|c|c|c|}
\hline & \multicolumn{2}{|c|}{ China $n=302$} & \multicolumn{2}{|c|}{ Germany $n=154$} & \multicolumn{2}{|l|}{$\underline{\text { USA }}$} & \multicolumn{2}{|l|}{$\frac{\text { Vietnam }}{n=350}$} & \multirow[b]{2}{*}{$F$} & \multirow[b]{2}{*}{$\eta^{2}$} \\
\hline & $M$ & $S D$ & $M$ & $S D$ & $M$ & $S D$ & M & $S D$ & & \\
\hline Storytelling & $2.62^{1,2,3}$ & 0.56 & $3.09^{4}$ & 0.59 & $3.23^{1,4}$ & 0.68 & $2.95^{2,4}$ & 0.56 & 33.26 & 0.11 \\
\hline Resilience & 3.26 & 0.48 & 3.17 & 0.70 & $3.49^{3}$ & 0.69 & 3.22 & 0.75 & 3.25 & 0.01 \\
\hline Achievement & $4.64^{1,2,3}$ & 0.87 & $3.49^{1,2,4}$ & 0.88 & $4.39^{1,3,4}$ & 0.86 & $4.10^{2,3,4}$ & 0.89 & 61.53 & 0.17 \\
\hline Benevolence & $4.58^{2}$ & 0.83 & $4.81^{1,2}$ & 0.68 & $5.18^{1,3,4}$ & 0.61 & $4.49^{2,3}$ & 0.72 & 22.50 & 0.07 \\
\hline Conformity & $4.64^{3}$ & 0.79 & $3.62^{1,2,4}$ & 0.87 & $4.63^{3}$ & 0.84 & $4.45^{3}$ & 0.78 & 58.79 & 0.17 \\
\hline Hedonism & $4.56^{1}$ & 0.93 & 4.39 & 0.98 & $4.58^{1}$ & 0.90 & $4.19^{2,4}$ & 0.83 & 10.47 & 0.07 \\
\hline Power & $3.43^{2,3}$ & 1.09 & $3.13^{4}$ & 0.75 & $3.03^{1,4}$ & 1.01 & $3.46^{2,3}$ & 0.96 & 7.90 & 0.03 \\
\hline Security & $4.31^{3}$ & 0.77 & $3.84^{1,2,4}$ & 0.77 & $4.28^{3}$ & 0.77 & $4.42^{3}$ & 0.72 & 21.37 & 0.06 \\
\hline Self-Direction & $4.36^{2,3}$ & 0.87 & $4.64^{4}$ & 0.64 & $4.79^{1,4}$ & 0.70 & $4.43^{2}$ & 0.78 & 9.08 & 0.03 \\
\hline Stimulation & $3.90^{2,3}$ & 1.11 & $3.48^{1,2,4}$ & 1.02 & $4.36^{1,3,4}$ & 1.05 & $3.96^{2,3}$ & 0.94 & 14.83 & 0.05 \\
\hline Tradition & $3.64^{2,3}$ & 0.68 & $3.30^{1,2,4}$ & 0.80 & $4.04^{1,3,4}$ & 0.94 & $3.71^{2,3}$ & 0.76 & 19.02 & 0.06 \\
\hline Universalism & 4.53 & 0.76 & $4.37^{2}$ & 0.72 & $4.69^{3}$ & 0.65 & 4.53 & 0.75 & 3.50 & 0.01 \\
\hline
\end{tabular}

Note. Pairwise differences $(p<.05)$ are noted by the following superscripts. ${ }^{1}$ differs from Vietnamese group,

${ }^{2}$ differs from American group, and ${ }^{3}$ differs from German group, and ${ }^{4}$ differs from China group.

Table 2. Bivariate Correlations of Factors

\begin{tabular}{|c|c|c|c|c|c|c|c|c|c|c|c|}
\hline & 1 & 2 & 3 & 4 & 5 & 6 & 7 & 8 & 9 & 10 & 11 \\
\hline 1. Storytelling & 1.00 & & & & & & & & & & \\
\hline 2. Resilience & $.123 * *$ & 1.00 & & & & & & & & & \\
\hline 3. Achievement & -.049 & $.151 * *$ & 1.00 & & & & & & & & \\
\hline 4. Benevolence & $.217 * *$ & $.136 * *$ & $.243 * *$ & 1.00 & & & & & & & \\
\hline 5. Conformity & $<.001$ & $.078 * *$ & $.395 * *$ & $.386^{* *}$ & 1.00 & & & & & & \\
\hline 6. Hedonism & $130 * *$ & $.154 * *$ & $.298 * *$ & $.312 * *$ & $.182 * *$ & 1.00 & & & & & \\
\hline 7. Power & -.010 & -.007 & $.444 * *$ & .002 & $.126^{* *}$ & $.214^{* *}$ & 1.00 & & & & \\
\hline 8. Security & .043 & .033 & $.401 * *$ & $.306^{* *}$ & $.535 * *$ & $.186^{* *}$ & $.200 * *$ & 1.00 & & & \\
\hline 10. Stimulation & $.218 * *$ & $.181 * *$ & $.391 * *$ & $.314^{* *}$ & $.170 * *$ & $.369 * *$ & $.254 * *$ & $.241 * *$ & $.526 * *$ & 1.00 & \\
\hline 11. Tradition & $.113 * *$ & -.013 & $.089 * *$ & $.280 * *$ & $.468 * *$ & $.135^{* *}$ & .035 & $.333 * *$ & $.072 *$ & $.103 * *$ & 1.00 \\
\hline 12. Universalism & $.166^{* *}$ & $.146^{* *}$ & $.311 * *$ & $.521 * *$ & $.442 * *$ & $.264 * *$ & $.074 *$ & $.477 * *$ & $.459 * *$ & $.419 * *$ & $.291 * *$ \\
\hline
\end{tabular}

Note. $*$ indicates significant at $p<.05 ; * *$ indicates significant at $p<.01$

\section{Results}

Descriptive statistics were employed for our preliminary analyses (see Table 1 for means, standard deviations. $F$ values and $\eta^{2}$ effect sizes).

Prior to addressing the research purposes, the researchers calculated the bivariate correlations between the factors; see Table 2. All of the correlations were statistically significant, except for Storytelling and Achievement (-.049), Conformity $(<.001)$ and Power (-.010); Resilience and Power (-.007), Security (.033), and Tradition (-.013). The significant correlations ranged from 0.535 (Security and Conformity) to 0.072 (Tradition and Self-Direction).

\section{Group Differences}

To test for differences between countries, analyses of variances (ANOVA) were conducted. The Tukey-HSD, post hoc procedure $(p<.05)$ was employed to examine all possible pairwise differences. For each significant ANOVA, an effect size was calculated. Given the large number of ANOVA tests, the $p$ level required to reject the null hypothesis was set at $p<.001$ for each comparison (see Table 1). Specifically, there were significant differences across the four countries on Storytelling, with a large effect size $\left.F(3,885)=33.264, \eta^{2}=.0 .11\right)$, Resilience, with a small effect size, $\left(F(3,885)=4.849, \eta^{2}=.0 .01\right)$, Achievement $(F(3$, 
$\left.885)=61.531, \eta^{2}=.0 .17\right)$, Benevolence $(F(3,885)=22.497$, $\left.\eta^{2}=.0 .07\right)$, Conformity $\left.(F(3,885)=58.786), \eta^{2}=.0 .17\right)$, Hedonism $\left(F(3,885)=10.471, \eta^{2}=.0 .07\right)$, Power $(F(3,885)$ $\left.=7.898, \eta^{2}=.0 .03\right)$, Security $\left(F(3,885)=21.367, \eta^{2}=.0 .06\right)$, Self-Direction $\left(F(3,885)=9.081, \eta^{2}=.0 .03\right)$, Stimulation $\left(F(3,885)=14.829, \eta^{2}=.0 .05\right)$, Tradition $(F(3,885)=$ $\left.19.023, \eta^{2}=.0 .06\right)$, and Universalism $\left(F(3,885)=3.502, \eta^{2}\right.$ $=.0 .01)$. The effect sizes for the ten values ranged from a low of 0.01 (Universalism) to a high of 0.17 (Conformity and Achievement). In an examination of the means for each group, (see Table 1) the United States had the highest mean values for Storytelling $(M=3.23, S D=0.68)$, Resilience $(M$ $=3.49, S D=0.69)$, Benevolence $(M=5.18, S D=0.61)$, Conformity $(M=4.63, S D=0.84)$, Hedonism $(M=4.58, S D$ $=0.90)$, Self-Direction $(M=4.79, S D=0.70)$, Stimulation $(M=4.36, S D=1.05)$, Tradition $(M=4.04, S D=0.94)$, and Universalism $(M=4.69, S D=0.65)$. China had the highest mean value for Achievement $(M=4.64, S D=0.87)$. Vietnam had the highest mean values for Power $(M=3.40, S D=0.96)$ and Security: $(M=4.42, S D=0.72)$. The United States had the lowest mean value for Power $(M=3.03, S D=1.01)$. China had the lowest mean values for Storytelling $(M=2.62$, $S D=0.56)$ and Self-Direction $(M=4.36, S D=0.87)$. Germany had the lowest mean values Resilience $(M=3.17$, $S D=0.70)$, Achievement $(M=3.49, S D=0.88)$, Conformity $(M=3.62, S D=0.87)$, Security $(M=3.84, S D=0.77)$, Stimulation $(M=3.48, S D=0.77)$, Tradition $(M=3.30, S D=$ $0.80)$, and Universalism $(M=4.37, S D=0.72)$. Vietnam had the lowest mean values for Benevolence $(M=4.49, S D=$ $0.72)$ and Hedonism $(M=4.19, S D=0.72$; see Table 1$)$.

An additional analysis revealed gender differences in several variables, after using a Bonferroni adjustment to account for Type I errors. Specifically, female participants tended to have statistically significantly higher measures of Storytelling $(t(888)=-3.62)$ and male participants tended to have higher Resilience $(t(888)=3.69)$ and Power $(t(888)=$ $3.44)$. All other measures revealed no significant differences between gender.

\section{Structural Equation Modeling}

To examine the extent to which the relationship between storytelling and resilience is mediated by values, an exploratory, saturated model was created to conceptualize a meditational model between Storytelling and Resilience, including the Value Factors. In the saturated model, all possible paths and covariances between the variables are included.

This model revealed a non-significant chi-square test $(p=$
0.24), which would indicate good model fit, as did the CFI (0.998). However, the RMSEA indicated mediocre fit (0.068); see Table 3.

Table 3. Model Fit of Models

\begin{tabular}{|c|c|c|c|c|c|c|}
\hline & Chi-Square & $d f$ & $p$ & RMSEA & CFI & AIC \\
\hline $\begin{array}{c}\text { Saturated } \\
\text { Model }\end{array}$ & 5.107 & 1 & 0.24 & $\begin{array}{c}.068 \\
(.020, .131)\end{array}$ & .998 & 159.107 \\
\hline $\begin{array}{c}\text { Trimmed } \\
\text { Model }\end{array}$ & 24.608 & 13 & 0.26 & $\begin{array}{c}.032 \\
(.011, .051)\end{array}$ & .996 & 154.608 \\
\hline $\begin{array}{c}\text { Final } \\
\text { Model }\end{array}$ & 21.173 & 11 & .032 & $\begin{array}{c}.032 \\
(.009, .053)\end{array}$ & .994 & 109.173 \\
\hline
\end{tabular}

$p=.05$

As the researchers were interested in a more parsimonious model, the next model tested was a Trimmed model, in which all non-significant paths were removed from the analyses, although all covariances were included. In this model, the chi-square test was non-significant $(p=0.26)$ and the RMSEA (0.032) and CFI (0.996) indicated a good-fitting model. In addition, a comparison of the AIC demonstrated that the Trimmed model (AIC $=154.608)$ was a slightly better fit to the data than the Saturated model (AIC $=159.107$; see Table 3 ).

Finally, the researchers tested a model that included only the significant path estimates and covariances from the Trimmed model. In the Final Model, the chi-square test was significant $(p=0.032)$, however, this is not uncommon when the sample size is greater than 200. The RMSEA (0.032) and the CFI (0.994) both indicated a good fitting model. In addition, a comparison of the AIC (109.173) indicated that the Final Model was the best fit to the data; see Table 3.

The Final Model (see Figure 2) is a partial meditational model of Storytelling to Resilience. Specifically, Stimulation mediates part of the relationship between Storytelling and Resilience. In addition, Storytelling influences Benevolence, Hedonism, Self-Direction, Tradition, and Universalism, and Achievement and Power influence Resilience. Conformity and Security were not included in the Final Model, as there were no significant paths.

The direct path between Storytelling and Resilience had a standardized path estimate of 0.102 (see Figure 2), which was mediated by the indirect path of Storytelling to Stimulation (0.235) and Stimulation to Resilience (0.126). The standardized estimates from Storytelling to Benevolence (0.231), Hedonism (0.143), Self-Direction (0.241), Tradition (0.116), and Universalism (0.183) were small to moderate. The standardized path estimates from Achievement (0.153), Power (-0.106), and Stimulation (0.126) to Resilience were small. 


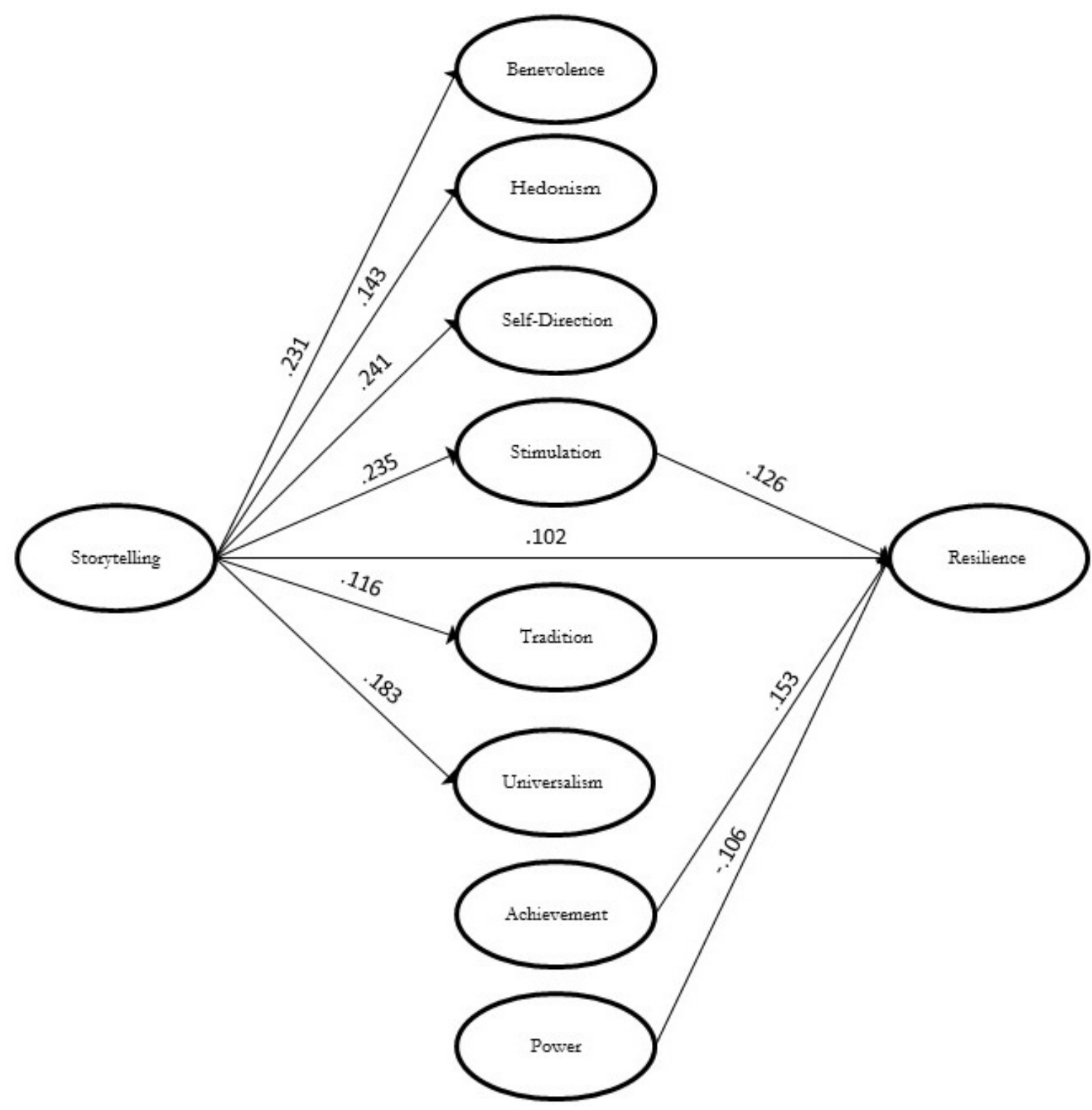

Figure 2. Final Model with Standardized Path Estimates

The covariances included in the Final model ranged from 0.422 (Achievement and Power) to 0.042 (Achievement and Tradition).

\section{Multiple Group Analysis}

The multiple group analysis was completed in a series of steps in which more of the model parameters were constrained to be equal across the country groups. The unconstrained model, in which all countries were allowed to vary across path estimates and error variances had a significant chi-square value $(p<.001)$ and the RMSEA $(0.034)$ and CFI (0.975) indicated good model fit (See Table 4).

When the path estimates were held constant across the countries, the chi-square value was significant $(p<.001)$ and the RMSEA (0.028) and CFI (0.973) indicated good model fit. In addition, the AIC (414.893) indicated a better model fit than the unconstrained model (AIC $=441.418)$. Finally, there was a significant difference in the change in chi-square value $(p<.001)$.

The next stage, in which the error variances were held constant across groups, revealed a significant chi-square test $(p<.001)$ and the RMSEA indicated reasonably good fit (0.041). However, the CFI indicated a poor fit (0.860), and the AIC indicated a poorer fitting model (531.292) than the invariance of path estimates model.

Thus, the results of the multiple group analyses indicates that the Final Model path estimates were invariant across groups, but the error variances of the mean values were not invariant. Thus, the relationships between Storytelling and the values, and between the values and Resilience, remained constant between the four groups of students. 
Table 4. Final Model Tests of Invariance

\begin{tabular}{|c|c|c|c|c|c|c|c|}
\hline & Chi-Square & $\mathrm{df}$ & $\mathrm{p}$ & RMSEA & CFI & AIC & $\begin{array}{c}\text { Chi-Square } \\
\text { Difference }\end{array}$ \\
\hline $\begin{array}{c}\text { Model 1: } \\
\text { Unconstrained Model }\end{array}$ & 95.418 & 47 & $<.001$ & $\begin{array}{c}.034 \\
(.024, .044)\end{array}$ & .975 & 441.418 & .302 \\
\hline $\begin{array}{c}\text { Model 2: } \\
\text { Invariance of Path } \\
\text { Estimates }\end{array}$ & 128.893 & 77 & $<.001$ & $\begin{array}{c}.028 \\
(.019, .036)\end{array}$ & .973 & 414.893 & $<.001 * *$ \\
\hline $\begin{array}{c}\text { Model 3: } \\
\text { Invariance of Error } \\
\text { Variances }\end{array}$ & 443.292 & 176 & $<.001$ & $\begin{array}{c}.041 \\
(.037, .046)\end{array}$ & .860 & 531.292 & $<.001 * *$ \\
\hline
\end{tabular}

\section{Discussion}

The current research confirmed that there are significantly different relationships between Eastern and Western cultures on childhood experiences of storytelling, adult resilience and values. The data suggest amount and intensity of storytelling was expressed most by college students in this ranking: Americans, Germans, Vietnamese, and Chinese.

The study is the first known study to compare Eastern and Western storytelling experiences so there are no other study's results to compare. Here are some speculations why these results differ. A previous study [3] found that using storytelling, a student-centered approach is not widely used in Chinese classrooms which tend to be less culturally diverse and rely more on teacher-centered learning through lecture than Western classrooms. Kim [13] who conducted case studies of American and Asian teachers found that American teachers are more individualistic and idiosyncratic in their approaches to teaching. Less storytelling in the home for Chinese and Vietnamese might be due to cultural factors because it is the perceived in Asia that the role of the school is to provide literacy instruction.

The results suggest Americans and Germans as children were significantly told more religious stories than the two other groups. This finding is consistent with Mottley and Telfer [18] who found that $50 \%$ of American prospective teachers reported that the most common storytellers outside of the home were church leaders. Similarly, Subedi [32] who studied the beliefs and practices of American, white female prospective teachers found that the sense of religion was Christian and a product of their family beliefs and socialization in churches.

The data suggest Americans reported having the highest degree of resilience. Germans, Chinese and Vietnamese reported having about the same degree of resilience. There are no known, cross-cultural quantitative studies addressing this issue. However, the similarity of resilience may be explained by the phenomenon of globalization. That is, the differences between cultures are becoming smaller $[8,17]$. The sample for the studies consisted of a homogenous group of mostly female college students not representative of the population. There is likely to be less difference in the trait of resilience for college students than the general population.

The current research found that there are statistically significant differences between cultural groups on values.
The Eastern cultures of China and Vietnam tend more to preferences for the values of Conformity, Achievement, Power and Security. The Western cultures of America and Germany tend more to the preferences for the values of Self-Direction and Benevolence. In general Eastern culture tends more to values of conservatism and Western culture tends more to values of openness to change. These findings are consistent with previous research $[12,28]$.

The current study examined the mediator effects of values for the relationship between storytelling and resilience in college students. As expected the best model from this study indicated storytelling and resilience were partially mediated by values. Although no previous studies have examined directly the mediator effects of values for the relationship between storytelling and resilience, the results are consistent with earlier studies suggesting a relationship between values and resilience $[4,19,25,35]$. Given the results found of negative associations between storytelling and the value Achievement, and resilience and the values of Power and Tradition, bi-directional causality was evident. The best model from the current study supports the mediator effects of values between storytelling and resilience. The current finding indicates that college students who report having significant childhood experiences of storytelling, and prefer openness to change values such as Benevolence, Self-Direction, and Stimulation perceive recalling, or telling stories more often for improving resilience. On the other hand, college students who report having less significant childhood experiences of storytelling, and prefer conservative values such as Conformity, Tradition and Security perceive recalling, or telling stories less often for improving resilience. These findings are consistent with research that showed strong relationship between openness to change values and preference for student-centered teaching approaches like storytelling $[14,15,34]$. The data suggest that the perception that one can draw upon remembrances of stories for improving resilience is related to a combination of factors: one's gender, values, individual and cultural differences. For example, the data suggest females had more childhood experiences of storytelling and higher resilience than males.

\section{Limitations and Future Research}

The present study is certainly not without limitations. 
The first limitation is that the study's correlational cross-sectional nature prohibits drawing any causal relationships among the variables. Interpretation of the results of mediational analyses on cross-sectional data must always proceed with caution. Future longitudinal or experimental studies will facilitate more causal evaluations. The resilience and values measures required subjective self-perceptions of one's inner emotional state which are difficult to quantify on a Likert scale and limits responses. The storytelling questionnaire required adult participants to reflect on childhood events that occurred a long time ago. Secondly, only college education majors, mostly female (78.4\%), were included in the study. Thus, these findings should not be extrapolated to populations with larger proportions of males, other income and educational-level groups. Subsequent research studies should include a control group of participants from a wider educational and socio-economic range or a clinical population experiencing stress such as dropouts or students receiving counseling or tutorial services. Resilience manifests itself most in the face of adversity. The psychological benefits of teaching and counseling adults with storytelling are still not clearly understood. Future researchers might investigate the effects of storytelling interventions upon student retention, well-being, resilience and values using a pre-posttest experimental design.

\section{Implications}

Increased teacher training in storytelling for developing language, literacy, and resilience is needed. Researchers should explore how different cultures' values influence the ways they express and teach stories. Unfortunately, this study highlights the fact that it's unlikely college students who have not had significant childhood experiences of storytelling will use storytelling in their own teaching or know how to encourage and teach parents to incorporate family storytelling for literacy $[2,33]$. Prospective educators should reflect on their teaching practices by telling their autobiographical stories [Cochran-Smith [6] and Nieto [21] as the evidence suggests it will increase their resilience.

\section{Conclusions}

This study contributes to the field by adding information about the relationships between storytelling, values, and resilience. The evidence suggests that storytelling may leverage retention strategies by boosting the resilience of the learner, although much remains to be learned on how to do this. Storytelling is the oldest from of teaching, and adult educators should not dismiss its potential as both a research method and practical intervention. Also, the evidence suggests that there is value to open mindedness and making the effort to make storytelling for resilience a part a teacher's toolbox.

\section{REFERENCES}

[1] Arbuckle, J. L. (2013). IBM® ${ }^{\circledR}$ SPSS ${ }^{\circledR}$ Amos $^{\text {TM }} 22$ User's Guide. Chicago, IL: IBM.

[2] Stanley, N. \& Dillingham, B. (2013, April). Family storytelling: A powerful parenting strategy for developing intellect, language, literacy, and values. Language Magazine. Retrieved from http://languagemagazine.com/?page_id=6133

[3] Nguyen, K., Stanley, N., \& Stanley, L. ( 2014 ). Storytelling in teaching Chinese as a second/foreign Language. Linguistic and Literature Studies. 2(1),29-38. doi.org/10.13189/1ls.2014.020104Authors (2015)

[4] Nguyen, K. ,Stanley, N., Stanley, L., \& Wang, Y. (2015). Resilience in language learners and the relationship to storytelling. Cogent Education, 2,1-16. doi.org/10.1080/2331186X.2014.991160

[5] Bruner, J. (1996). The culture of education. Cambridge, MA: Harvard University Press.

[6] Cochran-Smith, M. (2000). Blind vision: Unlearning racism in teacher education. Harvard Educational Review, 70(2), 157-190. doi.org/10.1016/s0742-051x(02)00091-4

[7] Duke, M.L., Lazarus, A., \& Fivush, R. (2008). Knowledge of family history as a clinically useful index of psychological well-being and prognosis: A brief report. Psychotherapy Theory, Research, Practice, Training, 45,268-272. doi: 10.1037/0033-3204.45.2.268

[8] Fischer, R., \& Schwartz, S. (2011). Whence Differences in value priorities? Individual, cultural, or artifactual sources. Journal of Cross-Cultural Psychology, 42(7), 1127 -1144. doi.org/10.1177/0022022110381429

[9] Fletcher, D., \& Sarkar, M. (2013). Psychological resilience: A review and critique of definition, concepts and theory. European Psychologist, 18, 12-23. doi: $10.1027 / 1016-9040 / \mathrm{a} 000124$

[10] Frude, N., \& Killick, S. (2011). Family storytelling and the attachment relationship. Psychodynamic Practice, 17, 441-455. doi.org/10.1080/1453634.2011.609025

[11] Gay, G. (2010). Culturally responsive teaching: Theory, research, and practice. New York, NY: Teachers College Press.

[12] Hofstede, G. H., \& Hofstede, G. (2001). Culture's consequences: Comparing values, behaviors, institutions, and organizations across nations. Thousand Oaks, CA: Sage Publications.

[13] Kim, Y. S. (2009). The relationship between home literacy practices and developmental trajectories of emergent literacy and conventional literacy skills for Korean children. Reading and Writing, 22(1), 57-84.

doi.org/10.1007/s11145-007-9103-9

[14] Lietz, P., \& Matthews, B. (2010). The effects of college students' personal values on changes in learning approaches. Research in Higher Education, 51(1), 65-87. doi.org/10.1007/s11162-009-9147-6 
[15] McDrury, A. \& Alterio, M. (2002). Learning through storytelling in higher education: using reflection and experience to improve learning. New York, NY: Routledge

[16] Meyer, K. M., Licklider, B. L., \&Wiersema, J. A. (2008). The Impact of stories: Experiences of post-secondary students in resiliency development education. Journal of Ethnographic \& Qualitative Research, 3(1), 37-47.

[17] Morris, M.W. (2014). The essence of culture: Foundation or fallacy? Journal of Cross-Cultural Psychology, 45(1), 14-24. doi.org/10.1177/0022022113513400

[18] Mottley, R., \& Telfer, R. (1997). Storytelling to promote emergent literacy: Prospective teachers' storytelling experiences and expectations. In K. Camperell, B.L.Hayes, \& R. Telfer (Eds.), Promises, progress and possibilities: Perspectives of literacy education. Seventeenth Yearbook of the American Reading Forum (127-147). Logan, Utah: American Reading Forum

[19] Narra-Tumma, P. \& Claudius, M. (2013). A qualitative examination of Muslim graduate international student's experiences in the United States. International Perspectives in Psychology: Research, Practice, Consultation, 2, 132-147. doi: 10. 1037/ipp0000003

[20] National Storytelling Network (n.d.). What is storytelling? (Website].Retrieved from http://www.storynet.org/resources/ whatisstorytelling.html

[21] Nieto, S. (2003). What keeps teachers going? New York, NY: Teachers College Press.

[22] Noltemeyer, A. L., \& Bush, K.R. (2013). Adversity and resilience: A synthesis of international research. School Psychology International. 34(5), 474-487. doi: 10.1177/0143 04312472758

[23] Ong, W. (1982). Orality and literacy: The technologization of the word. London, England: Methuen.

[24] Palmer, B. C., Harshbarger, S. J., \& Koch, C. A. (2001). Storytelling as a constructivist model for developing language and literacy. Journal of Poetry Therapy,14(4), 199-212. doi.org/10.1023/a:1017541527998

[25] Perry, K. (2008). From storytelling to writing: Transforming literacy practices among Sudanese refugees. Journal of Literacy Research, 40(3), 317-358. doi.

\section{$10.1080 / 10862960802502196$}

[26] Rozin, P. (2000). Evolution and adaption in the understanding of behavior, culture, and mind. American Behavioral Scientist, 43(6), 970-986. doi.org/10.1177/00027640021955 702

[27] Schwartz, S. H. (1992). Universals in the content and structure of values: Theory and empirical tests in 20 countries. In M. Zanna (Ed.), Advances in experimental social psychology, 25, 1-65, New York, NY: Academic Press.

[28] Schwartz, S. H., \& Bardi, A. (2001). Value hierarchies across cultures: Taking a similarities perspective. Journal of Cross-Cultural Psychology, 32, 268-290. doi: 10.1177/0022022101032003002

[29] Schwartz, S. H. (2011). Studying values: Personal adventure, future directions. Journal of Cross-Cultural Psychology, 42(2), 307-319. doi.org/10.1177/0022022110396925

[30] Schwartz, S. (2014). Values: Cultural and individual. Journal of Cross-Cultural Psychology, 45(1), 5-13. doi: org/10.1017/cbo9780511974090.019

[31] Smith, B.W., Dalen, J., Wiggins, K., Tooley, E., Christopher, P., \& Bernard, J. (2008). The brief resilience scale: assessing the ability to bounce back. International Journal of Behavioral Medicine, 15:194-200. doi:10.1080/10705500802222972

[32] Subedi, B. (2006). Preservice teachers' beliefs and practices: Religion and religious diversity. Equity and Excellence in Education, 39, 227-238. doi:10.1080/10665680600788495

[33] Tin, H. W., Nonis, K. P., Lim, S.E., \& Honig, A. S. (2013) Teachers' perceptions of the importance of stories in the lives of children in Myanmar. Early Child Development and Care, 183(10), 1449-1467. doi: 10.1080/ 03004430.2013.788818

[34] Yeung, A, S, Craven, R. Kaur, G. (2014). Teachers' self-concept and valuing of learning: Relations with teaching approaches and beliefs about students, Asia-Pacific Journal of Teacher Education, 42(3), 305-320, doi:10.1080/1359866X.2014.905670

[35] Zevenbergen, A. A., Haman, E., \& Olszanska, A. A. (2011). Middle class Polish and American mothers' beliefs regarding parent child narratives, Journal of Cross Cultural Psychology,43,978-998..doi:10.1177/0022022111416005 